\title{
Deslocamentos antropofágicos na literatura marginal periférica
}

\author{
Anthropophagic displacements in peripheral marginal literature
}

Desplazamientos antropofágicos en la iterature marginal periférica

Rejane Pivetta de Oliveira 1

Universidade Federal do Rio Grande do Sul, Porto Alegre, RS, Brasil.

\section{RESUMO}

O fenômeno da literatura marginal periférica emerge no sistema literário brasileiro contemporâneo como um movimento que confronta a tradição canônica da literatura, todavia apropriada como um elemento de legitimação. Neste artigo, buscamos evidenciar que os atos de instituição da literatura marginal periférica mantêm articulações com a experiência modernista, operando deslocamentos literários e culturais associados ao conceito de antropofagia, formulado por Oswald de Andrade como proposta de interpretação da cultura brasileira.

Palavras-chave: Literatura marginal periférica. Antropofagia. Cultura. Política. Estética.

\section{ABSTRACT}

The phenomenon of marginal peripheral literature emerges in the contemporary Brazilian literary system as a movement that confronts the canonical tradition of literature, however appropriated as an element of legitimation. In this paper, we seek to highlight that the acts of institutionalization of the marginal peripheral literature maintains articulations with the modernist experience, operating literary and cultural displacements associated to the concept of anthropophagy, formulated by Oswald de Andrade as a proposal of interpretation of the Brazilian culture.

Keywords: Marginal peripheral literature. Anthropophagy. Culture. Politics. Aesthetics.

\section{RESUMEN}

El fenómeno de la literatura marginal periférica emerge en el sistema literario brasileño contemporáneo como un movimiento que confronta la tradición canónica de la literatura, todavia apropiado como un elemento de legitimación. En este artículo, buscamos resaltar que los actos de institución de la literatura marginal periférica mantienen articulaciones con la experiencia modernista, operando desplazamientos literarios y culturales asociados con el concepto de antropofagia, formulado por Oswald de Andrade como una propuesta de interpretación de la cultura brasileña.

Palabras clave: Literatura marginal periférica. Antropofagia. Cultura. Política. Estética. 


\section{Problematizações iniciais}

A literatura marginal contemporaneamente produzida no Brasil tem como aspecto característico o fato de ser produzida no espaço da favela, trazendo à tona um olhar interno sobre a experiência de viver à margem dos centros sociais e culturais. Essa é uma diferença fundamental em relação à produção de escritores que, valendo-se de uma temática afeita à experiência dos marginalizados, o fazem desde um lugar social privilegiado, assumindo a voz dos sujeitos historicamente silenciados. A recorrência com que a pobreza e a exclusão são representadas na literatura brasileira acaba por expor um dilema: por um lado, a classe dos intelectuais burgueses, que detém o controle dos meios de representação legitimadores de seu privilégio; de outro, as camadas pobres, reduzidas ao papel de vítimas, alijadas de protagonismo nas produções artísticas e intelectuais que as "representa".

Todavia, as ações e movimentos culturais originados contemporaneamente no interior das comunidades periféricas ${ }^{1}$ resultam em formas de representação e mecanismos de intervenção na vida social que reconfiguram a imagem de pobreza, violência e exclusão com a qual o cenário das favelas tem sido comumente identificado. Os inúmeros saraus, festivais de música, dança, cinema, mostras e toda uma série de outros eventos afirma a favela como "local da cultura" 2 , em uma clara tomada de posição face aos padrões culturais hegemônicos. Contudo, não é o caso de negar os monumentos e canais de afirmação da tradição cultural canônica, mas de provocar o deslocamento de suas fronteiras. Ou seja, não se trata apenas de afrontar o sistema e denunciar as estratégias de dominação e instituição do cânone, mas de derrubar as barreiras que tornam invisíveis e operam a negação da cultura produzida nas margens do sistema, tanto mais quando se trata da atividade escrita, cingida ao universo letrado das elites. Nos termos aqui propostos, a produção literária dita marginal e periférica é definida a partir das condições próprias em que se dá a sua emergência no espaço de morros e favelas, onde a literatura se inscreve como um projeto e um programa de "ação estética", que visa a "dar voz ao grupo social de origem dos escritores" (NASCIMENTO, 2009, p. 105). Tal fenômeno exige que a literatura seja interpretada antropologicamente, em conexão mais densa com as práticas por meio das quais escritores e comunidades organizam e dão sentido à vida coletiva.

\footnotetext{
1 Por periferia referimo-nos aqui aos espaços sociais localizados à margem dos grandes centros urbanos que abrigam comunidades heterogêneas, afetadas por um quadro de exclusão, pobreza e precariedade das condições de infraestrutura.

2 Referência ao título da obra de Homi Bhabha O local da cultura (1998).
}

A efervescência do movimento, atestada não apenas pelos inúmeros eventos culturais espalhados pelas periferias, mas também pelo expressivo número de obras e escritores que daí emergem, tem despertado o interesse da crítica. A reflexão sobre o tema é encontrada, sobretudo, em artigos de jornais e periódicos científicos, dissertações e teses acadêmicas, concentrando-se na abordagem de aspectos relativos à representação da violência, da marginalidade $\mathrm{e}$ da desigualdade em obras de autores específicos. Também as relações entre literatura e política, ao lado do papel do intelectual face às vozes marginais são temas privilegiados. A relevância dessa literatura é reforçada pelo caráter de resistência às formas canônicas de expressão, ao lado da ação estético-cultural a ela associada, com vistas a um projeto de transformação da realidade ${ }^{3}$.

No entanto, esse movimento precisa ser apreendido em sua dinâmica histórica, como um daqueles "momentos decisivos" do sistema literário brasileiro. Dada a persistência e impactos do movimento, é necessário articulá-lo dialeticamente à nossa tradição literária, vinculando-o ao projeto de pensar a cultura brasileira, face às condições históricas do presente. Para tanto, propomos analisar o fenômeno em dois momentos principais: a) no marco inaugural do movimento, em 2001, quando da publicação do Manifesto intitulado "Terrorismo Literário", assinado por Ferréz, na edição especial da Revista Caros Amigos; b) quando do lançamento, em 2007, do "Manifesto da Antropofagia Periférica" e da Semana de Arte Moderna da Periferia, a cargo de Sérgio Vaz. Os atos de instituição da literatura marginal periférica deixam evidentes articulações com as vanguardas e o modernismo brasileiro de 1922, haja vista o recurso aos manifestos; a proposta de revisão crítica da tradição cultural brasileira; a reconfiguração das relações entre literatura e sociedade. Desse modo, buscamos evidenciar a apropriação da experiência modernista, a partir de deslocamentos literários e culturais associados ao conceito de antropofagia, de Oswald de Andrade, cujos termos de interesse para a abordagem aqui proposta examinamos a seguir.

\section{Deslocamentos antropofágicos}

A importância de Oswald de Andrade para a literatura brasileira não se restringe à sua produção ficcional. Uma

\footnotetext{
Além do número significativo de artigos acadêmicos, teses e dissertações já produzidas sobre o tema, facilmente acessadas nos periódicos da área, nas páginas dos Programas de Pós-Graduação em Letras e no Banco de Teses da Capes, contamos hoje uma produção crítica relevante em livros (por exemplo, Vozes marginais na literatura, 2009, de Erica Peçanha do Nascimento; Escritos à margem: a presença de autores de periferia na cena literária brasileira, 2013, de Paulo Roberto Tonani do Patrocínio; Literatura e periferias, 2019, organizado por Lucía Tenina e Regina Dalcastagnè)
} 
parte relevante de sua obra são os Manifestos e ensaios críticos-filosóficos, fundamentais para o conhecimento das ideias do autor sobre a cultura e a literatura brasileira.

Já no Manifesto da Poesia Pau-Brasil, de 1924, Oswald propugna a mistura entre o primitivo e o civilizado, a floresta e a escola, a cultura nativa e a intelectualizada. De outra parte, na valorização dos estados originais "Nenhuma fórmula para a contemporânea expressão do mundo. Ver com olhos livres" (ANDRADE, 1990, p. 42) -, notamos claramente uma posição contrária às visões oficiais, aos "gabinetismos", aos artificialismos, à cultura livresca que caracteriza a formação europeia que o autor renega em nome da "contribuição milionária de todos os erros" (ANDRADE, 1990, p.41). Oswald sintetiza uma concepção de cultura brasileira: cultura de tradição europeia, mas dotada de uma originalidade primitiva marginalizada, que constitui a sua matéria prima de exportação: a poesia pau-brasil. Oswald transforma o produto da exploração predatória da colônia em matéria prima da invenção, uma operação que reverte o mal em bem, o negativo em positivo - o que mais tarde ele vai elaborar conceitualmente, no Manifesto Antropófago, de 1928, em termos da transformação do Tabu em Totem. Nele o autor vai mais fundo, pois elabora um conceito, uma categoria teórica para pensar a cultura brasileira, nunca isenta de tensões.

Antes de mais nada, a antropofagia é um princípio de comunhão, de unidade coletiva. Também é um princípio de alteridade, o interesse está no outro, no que difere, no que não é o eu, no que não pertence ao eu: "Só me interessa o que não é meu. Lei do homem. Lei do antropófago" (ANDRADE, 1990, p. 47). Trata-se, ainda, de um antídoto contra a castração do corpo, contra as proibições e os cerceamentos morais e religiosos: contra os "males catequistas, a peste dos povos cristianizados". A "vacina" antropofágica é justamente o antídoto que reage à doença do espírito sem corpo. A Antropofagia é uma operação de subversão da ordem, da lei - o Totem -, erigindo em seu lugar o Tabu, as proibições que cerceiam as liberdades individuais e coletivas. Por fim, a grande lição que aprendemos do Manifesto é que a antropofagia é a absorção do inimigo, o qual deve ser assimilado para que se estabeleça uma ordem diversa, mediante um gesto ritual, já que o inimigo é digno de todo o respeito.

No contexto da vanguarda modernista brasileira, a antropofagia oswaldiana é um dispositivo para pensar as questões de dependência cultural, a situação de sociedade colonizada, reprimida, tiranizada pelo inimigo europeu, que deve ser deglutido, devorado. A antropofagia é, sobretudo, uma reação, uma "vacina" contra a violência estrutural do processo colonizador.

Para uma compreensão mais ampla da antropofagia oswaldiana como categoria de interpretação cultural, é necessário entender como funciona a antropofagia literal, as funções do rito antropofágico nas sociedades primitivas ${ }^{4}$. Não se trata apenas de matar o inimigo para absorver dele a força e a coragem, como comumente é dito. É preciso entender o sentido e a função dessa prática, que envolve todo um esquema relacional, não limitado à predação entre humanos. Envolve também a predação de outros seres com capacidades subjetivas, pois, no universo indígena, não só os humanos têm intenção, uma consciência e um ponto de vista, mas também os animais e todos os seres da natureza são concebidos com os mesmos atributos humanos, todos são dotados de ação, intenção e perspectiva própria.

Em segundo lugar, é preciso entender que os sentimentos de honra e vingança estão em jogo na antropofagia. Porém, a guerra e a devoração antropofágica não têm nada a ver com a posse de terras e bens, não se relaciona com nenhum sentido de propriedade. $\mathrm{O}$ objetivo da guerra é o festim antropofágico - "a alegria é a prova dos nove", mote tantas vezes repetido no Manifesto Antropófago. Segundo esclarece Carlos Fausto, os inimigos eram devorados em grandes festas, em um momento de reunião e de articulação de aldeias, o que envolvia um longo período de preparação. Era preciso primeiro familiarizar-se com o inimigo, o qual é resguardado, cuidado e tratado muito bem antes da devoração - não por sadismo, mas para que o seu espírito possa ser controlado. A captura deve ser a do espírito, principalmente, o seu matador deve conseguir assumir a perspectiva de sua presa, que se transforma em uma espécie de espírito auxiliar. Portanto, a antropofagia é uma operação que não envolve apenas comer de fato, mas fazê-lo também simbolicamente. Tanto é assim que o matador, após matar simbolicamente - ou seja, se apossar do espírito de sua vítima - era proibido de comer-lhe a carne.

Se para nós é chocante a morte e a devoração como atos públicos, para os ameríndios isso tem uma importância crucial, pois significa o desenvolvimento das capacidades criativas, a produção de sujeitos mais plenos, é um ato, enfim, de fertilização. O rito antropofágico envolve tanto identificação como negação do outro, é dessa dialética que emerge o novo sujeito afetado pelas "capacidades subjetivas da vítima" (FAUSTO, 1999, p.81). O antropófago está definitivamente marcado por subjetividades outras. Se tivermos em vista o sentido literal da antropofagia, fica mais claro o modo como Oswald

\footnotetext{
4 As ideias aqui sintetizadas sobre o ritual antropofágico dos povos indígenas estão detalhadas no artigo "Cinco séculos de carne de vaca: antropofagia literal e antropofagia literária", de Carlos Fausto, publicado originalmente na Revista Nuevo Texto Crítico, em 1999, posteriormente compilado no livro Antropofagia hoje: Oswald de Andrade em Cena (2011).
} 
de Andrade opera com esse conceito para problematizar duas tendências antagônicas, dominantes no pensamento sobre o Brasil de então, cujo imaginário se prolonga nos dias atuais, no contexto das sociedades globalizadas: de um lado, o nacionalismo regressivo (essencialista, ufanista, xenófobo); de outro, a simples subserviência ao estrangeiro, em nome de uma cultura sintonizada com os fluxos internacionais dominantes. O rito antropófogo diz, portanto, do processo de assimilação do outro, do jogo de reconhecimento e diferença em relação ao outro.

O programa antropofágico será revisto por Oswald, no prefácio de Serafim Ponte Grande, romance de 1928, escrito sob o espírito da antropofagia. No Prefácio de 1933, o autor, em uma espécie de exercício de autoanálise, mostra-se bastante crítico em relação à sua atuação como intelectual e artista dentro do modernismo e em relação à vanguarda antropofágica. Nesse Prefácio, Oswald afirma que os intelectuais revolucionários não passavam de boêmios, que ignoraram as massas e brincaram de "dar tiros entre rimas". Admite que fora um "palhaço de classe" e reconhece que a literatura de vanguarda serviu a interesses conservadores. É notável a capacidade de Oswald de se pensar enquanto artista, de avaliar o fracasso político de suas propostas estéticas, que ele identifica como apartadas da ação:

\footnotetext{
A situação "revolucionária" desta bosta mental sulamericana, apresentava-se assim: o contrário do burguês não era o proletário - era o boêmio! As massas, ignoradas no território e como hoje, sob a completa devassidão econômica dos políticos e dos ricos. Os intelectuais brincando de roda. De vez em quando davam tiros entre rimas.

$[\ldots]$

Fui com eles um palhaço de classe. Acoroçoado por expectativas, aplausos e quimeras capitalistas, o meu ser literário atolou diversas vezes na trincheira social reacionária (OSWALD, s.d., p. 9-12).
}

Na década de 1930, Oswald filia-se ao Partido Comunista, torna-se um artista engajado nas lutas proletárias. A obra mais representativa desse período é a peça $O$ rei da vela, que faz uma análise escrachada das classes dominantes a que o próprio escritor pertencia. A peça põe a nu, de maneira caricata, absurda, as engrenagens capitalistas que alimentam a exploração. A peça é uma crítica contundente à elite brasileira, que se dá por meio de personagens decadentes, inescrupulosos, representantes da tradição, da família e da propriedade, como podemos ver nesta fala de Abelardo I a Abelardo II.

ABELARDO I - O nosso. O que sacou às dez horas precisas da manhã. O dinheiro de Abelardo. O que troca de dono individual, mas não sai da classe. O que, através de herança e do roubo, se conserva nas mãos fechadas dos ricos... Eu te conheço e identifico, homem recalcado do Brasil! Produto do clima, da economia escrava e da moral desumana que faz milhões de onanistas desesperados e de pederastas... Com esse sol e essas mulheres!... Para manter o imperialismo e a família reacionária. Conheço-te, fera solta, capaz dos piores propósitos, Febrônio dissimulado das ruas do Brasil! Amanhã, quando entrares na posse da tua fortuna, defenderás também a sagrada instituição da família, a virgindade e o pudor, para que o dinheiro permaneça através dos filhos legítimos, numa classe só... (ANDRADE, 1973, p. 115-116).

A peça tem um evidente caráter alegórico, trata-se de uma alegoria antropofágica, capaz de revelar um conteúdo recalcado da História. Por meio de imagens fragmentadas, farsescas e esquemáticas, a peça trabalha com uma simplificação deliberada, monta um esquema explicativo paródico, baseado no funcionamento da sociedade capitalista. Para o crítico Sábato Magaldi (2004), a forma da peça monta um esquema para denunciar o quanto somos primários, o quanto respondemos, como sociedade, de maneira fácil, simplista e pouco reflexiva aos problemas e às contradições que persistem em nossa formação social. A última fala da peça é a do norte-americano: Oh! Good business! A perspectiva de continuidade dos negócios, tendo Abelardo II assumido o lugar de Abelardo I, casando-se, inclusive, com Heloísa, está intimamente associada à manutenção da ordem patriarcal, que tem no casamento o seu principal "recurso"(moeda de troca mesmo) para garantir a manutenção da propriedade.

Nos anos 1960, em plena ditadura, em 1967, a peça O Rei da vela é encenada pelo Teatro Oficina, grupo dirigido por José Celso Martinez, dando mostras da potência antropofágica na criação artística brasileira, quatro décadas depois no manifesto oswaldiano, legado que se mostra ainda fecundo nos dias de hoje.

\section{A literatura marginal-periférica na tradição literária e cultural brasileira}

Desde pelo menos o início dos anos 2000, as periferias brasileiras (com destaque para São Paulo) têm se transformado em "centros" de produção cultural e literária, de onde emergem artistas e escritores que alimentam todo um circuito de recepção e circulação de obras e eventos. A efervescência desse movimento não parece de somenos importância no sistema literário, pois, de fato, é possível verificar uma articulação política de escritores e agentes culturais periféricos, com a intenção consciente de participar do debate sobre a cultura, a literatura e a formação social brasileira. A preocupação em pensar os rumos da nação é uma tônica de nossa literatura, o que leva críticos como Antonio Candido (1997) a defini-la 
a partir de seu caráter "empenhado". A situação de país colonial que precisa constituir-se como nação e afirmar a sua cultura dá à literatura um certo sentido de "missão", o que, por certo, assume configurações próprias, em diferentes momentos históricos.

A literatura marginal periférica não é um fenômeno isolado, tampouco irrelevante, no sistema literário brasileiro, pois a atuação dos escritores tem repercussão não apenas em termos de renovação do repertório literário, como também promove uma tomada de posição que modifica o sentido e a função da literatura, no próprio gesto de luta de seus agentes contra as situações extremas de pobreza e violência a que os textos buscam dar voz. Nesse cenário é que situamos a reflexão sobre o papel assumido pelos escritores da periferia, que surgem afrontando o lugar burguês de consagração da literatura. Uma nova antropofagia é então postulada, que não rechaça o legado da tradição, mas trabalha para forjar um novo tipo de inserção da arte e da cultura na "comunidade dos excluídos".

O caráter periférico e marginal dessa literatura, assim designada por seus produtores, demanda uma análise em perspectiva histórica, situando essa produção no contexto da tradição da literatura brasileira, com a qual se estabelece em relação dialética, ao mesmo tempo de ruptura e reconhecimento. Na tradição literária brasileira, muitos escritores, de alguma forma, tomaram posição face à desigualdade que separa a elite dominante da massa dos excluídos, cisão entranhada na sociedade brasileira desde a sua formação. Nas páginas de nossos mais representativos escritores, a pobreza sempre se fez presente, conforme demonstra a coletânea $O s$ pobres na literatura brasileira, organizada por Roberto Schwarz (1983). Os textos reunidos nessa publicação explicitam problemas estruturais da sociedade brasileira: a desigualdade de classes e as relações de dominação e privilégio das elites.

Conforme salienta Schwarz, desde as suas primeiras manifestações, a literatura nacional deu mostras das profundas discrepâncias e contradições da nossa organização social, precária em seu processo de modernização. Se atentarmos para o conjunto de escritores elencados na coletânea, perceberemos que eles se distinguem não apenas pela dicção e pelo estilo, mas também pela posição no campo literário. Dos mais de trinta escritores presentes na coletânea de Schwarz ${ }^{5}$, nomes como Lima Barreto e Carolina Maria de Jesus evidentemente se destacam, por sua especial relação com a pobreza, dado que não se trata apenas de um tema, mas de uma condição vivida, com todas as suas consequências estigmatizantes, em termos sociais e literários.

\footnotetext{
Tais como Gregório de Matos, Castro Alves, Monteiro Lobato, Guimarães Rosa, Clarice Lispector, Ferreira Gullar, entre outros.
}

Lima Barreto, morador do subúrbio carioca e neto de escravos, traz na pele a marca de sua classe e, na voz literária, a preferência pela "marginália", lavrada em tom de revolta contra os moldes sociais e estéticos vigentes, fato que, por muito tempo, decretou que ocupasse posição secundária no campo literário brasileiro. A situação de Carolina Maria de Jesus é ainda mais emblemática, dadas as contingências de sua vida: mulher, negra, catadora de papel, favelada e de poucas letras. O livro de Schwarz traz uma proposta original de pensar a literatura brasileira a partir da pobreza como condição de nossa sociedade, merecendo que se lhe acrescentem novos capítulos, face às expressões literárias que emergem na cena contemporânea com grande fôlego, particularmente aquelas produzidas por escritores das periferias das grandes cidades brasileiras.

Explicitamente, o movimento da literatura marginal periférica adota estratégias de atuação que, em certa medida, recuperam o espírito de vanguarda da Semana de Arte Moderna, movimento extremamente fecundo, pelo que trouxe de renovação estética e aprofundamento da reflexão crítica sobre a cultura brasileira. Exemplo evidente do efeito prolongado da contaminação modernista é a reivindicação da antropofagia, de Oswald de Andrade, por movimentos de vanguarda surgidos a partir do final dos anos 1950, como o Concretismo (o Plano-Piloto para Poesia Concreta é de 1958), o Tropicalismo (cujo álbum-manifesto Tropicália é lançado em 1968) e outros grupos de resistência cultural e política, naqueles anos da ditadura, como o Teatro Oficina, responsável por levar ao palco, com grande ousadia estética, a peça $O$ rei da vela, conforme já mencionamos. Também na atitude transgressora dos chamados poetas marginais da década de 1970 contribuiu para desfazer o caráter solene da cultura e inventar novas formas de produção, recepção e circulação dos bens culturais.

Em todos esses momentos, ao longo do século XX, o modernismo introduz na produção literária, ensaística e crítica do Brasil um componente reflexivo que insiste em tomar as contradições, os impasses e as promessas mal cumpridas de nossa formação cultural como matéria privilegiada, em um processo contínuo de elaboração, com incidências que se fazem sentir na cena cultural contemporânea. Esse é o caso da intensa movimentação cultural que hoje acontece nas favelas e periferias das zonas urbanas, reconfigurando as tensões constitutivas da formação cultural brasileira. É sintomático que o movimento, em seus atos inaugurais, assuma os gestos próprios da literatura de vanguarda, inicialmente com o lançamento do Manifesto "Terrorismo literário", de Ferréz, publicado no volume Literatura marginal: talentos da escrita periférica, em 2005, seguindo o tom programático e desconstrutivo das vanguardas para festejar a chegada 
da literatura ao morro: "agora a gente fala, agora a gente canta, e na moral agora a gente escreve" (FERRÉZ, 2005, p.9).

Com um intervalo de seis anos desde o lançamento, em 2001, da edição especial da Revista Caros Amigos, com um dossiê sobre a literatura marginal, o movimento ganha novo impulso, com o Manifesto da Antropofagia periférica, lançado por Sérgio Vaz, por ocasião da Semana de Arte Moderna da Periferia. O evento, nos moldes da Semana de 1922 - inclusive com um cartaz que parodia o desenhado por Di Cavalcanti - reúne, em espaços da comunidade, sejam centros culturais, associações, bares ou praças, diversos artistas da periferia, em uma programação que inclui caminhada cultural, exposição de artistas plásticos, palestra, debates, oficinas e espetáculos de dança, mostras de vídeo, teatro, shows musicais, saraus, entre outras modalidades de eventos, todas elas com participação de artistas, intelectuais e agentes culturais da periferia.

O Manifesto de Sérgio Vaz, de 2007, tal como o Manifesto Antropófago, de Oswald de Andrade, de 1928, também é escrito na forma de aforismos e imitalhe parodicamente o estilo. Enquanto o Manifesto de Oswald diz que "Só a antropofagia nos une. Socialmente. Economicamente. Filosoficamente" (1990, p.47), o de Sérgio Vaz afirma: "A periferia nos une pelo amor, pela dor e pela cor" (2008, p.246). O sentido de comunhão invocado por Vaz tem a ver com a luta coletiva por reescrever a história: "Surge das ladeiras um povo lindo e inteligente galopando contra o passado. A favor de um futuro limpo, para todos os brasileiros" (2008, p.246). Na Antropofagia de Sérgio Vaz não há o tradicional questionamento "Tupy or not tupy". Todavia, o autor defende o "teatro que não vem do "ter ou não ter" (2008, p. 247) Em seu Manifesto, Vaz reivindica um outro tipo de consciência artística: "Contra a arte domingueira que defeca em nossa sala e nos hipnotiza no colo da poltrona./ Contra a barbárie que é a falta de bibliotecas, cinemas, museus, teatros e espaços para o acesso à produção cultural" (2008, p. 247).

Com base nos elementos aqui apresentados, parece sustentável a hipótese de que a antropofagia funciona como categoria agenciadora de novas relações entre o estético e o social, o central e o periférico. O movimento da literatura marginal contemporânea ganha, assim, uma dimensão política, capaz de colocar em xeque a própria instituição literária e seus mecanismos de legitimação do cânone, associados às estruturas sociais de dominação.

Críticos como Antonio Candido, Roberto Schwarz e Silviano Santiago apontam os impasses da vida social brasileira, gerados por uma colonização predatória, pela herança da escravidão e pela estrutura profundamente desigual da nossa sociedade, com profundas implicações na formação histórica da literatura brasileira. Para Candido, a situação de país colonial que sofre a imposição avassaladora dos padrões culturais da metrópole, ao lado de severas restrições à manifestação e à expansão da cultura local, mantida em estado de dominação, desencadeia uma série de tensões, sintetizadas na expressão "literatura de dois gumes": de um lado, o conformismo em relação à empresa colonizadora, em benefício da "civilização"; de outro, a manifestação de um desacordo em relação aos rumos da colonização (1987, p. 142). Para o autor, a cultura brasileira, oscilando entre o idealismo romântico, a "consciência amena" do atraso e a "consciência catastrófica" de país subdesenvolvimento, debate-se continuamente com a debilidade de suas instituições, a precariedade de suas condições materiais e as promessas mal cumpridas de realização futura.

As agudas contradições da sociedade brasileira, apreendidas na fatura das obras, tal como formula Candido, são analisadas de maneira rigorosa por Roberto Schwarz (1990) na leitura que faz do romance de Machado de Assis. O crítico assinala um certo sentido impróprio das ideias modernizadoras estrangeiras ("as ideias fora do lugar"), quando transplantadas para a realidade de um país escravocrata e socialmente atrasado, dando lugar a combinações disparatadas, artificiais e anacrônicas, que acabam por expor as estruturas arcaicas e enganosas, encarnadas em uma ideologia patriarcal, todavia ocultada (SCHWARZ, 1988). Na mesma chave que busca desentranhar dos traços formais da obra as dinâmicas sociais, culturais e históricas da sociedade, Schwarz analisa o romance Cidade de Deus, de Paulo Lins, intuindo uma nova situação: o mundo da neofavela é o nosso, nele originamse os marginais identificados como "sujeitos monetários sem dinheiro", os quais representam não mais o atraso, pois "são o resultado do progresso, o qual naturalmente qualificam"(1999, p. 171).

Em uma perspectiva não de todo coincidente, a análise de Silviano Santiago (2000) sobre os dilemas da colonização e os conflitos entre civilização e barbárie na América Latina parte da categoria de "entre-lugar", interpretada como potência ativadora de forças de descentramento e de desconstrução, que põem em xeque a primazia da literatura. Nessa medida é que o "entre-lugar" coaduna-se com o "caráter anfíbio" da literatura, que

tanto configura a carência socioeconômica e educacional da maioria da população do país, quanto define, pelo exercício impiedoso da autocrítica, o grupo reduzido e singular que tem exercido de uma forma ou de outra as formas clássicas de mando e governabilidade nas nações da América Latina (SANTIAGO, 2004, p. 66). 
Nesses termos, a identidade anfíbia da literatura fundamentalmente assinala a sua condição ambígua e instável, exatamente "entre" uma posição emancipatória e de dominação. Desse modo, a contradição que se mostra na obra não é apenas uma imagem dos desequilíbrios sociais, mas assinala ainda a dupla tônica ideológica da literatura, explicitando o lugar de privilégio desde onde ela própria elabora a sua crítica das desigualdades.

Essa contradição, insuperável do ponto de vista do registro letrado da ficção literária, em um contexto de precariedade material e educacional, demanda arranjos políticos e estéticos que ponham em xeque as hierarquias culturais que determinam os esquemas de representação, responsáveis por reservar ao outro posições previamente instituídas. Resta saber de que modo o lugar "entre", proposto por Silviano Santiago como categoria para pensar a cultura da América Latina, pode se converter em uma "assimilação inquieta e insubordinada, antropófaga" (2000, p.20), em benefício do outro colonizado ou excluído.

Silviano Santiago não desenvolve o argumento da assimilação "antropófaga", o que é feito, de maneira mais explícita, por Haroldo de Campos (2013), no ensaio "Da razão antropofágica: diálogo e diferença na cultura brasileira". O autor postula uma leitura do nosso passado colonial pelo viés a antitradição, que passa pelos desvãos, frestas e fissuras da história, reivindicando a antropofagia como princípio de alteridade e exercício de autocrítica, o que, no nosso entendimento, contém a sugestão de um "ímpeto marginal" extremamente fecundo e válido para compreendermos a produção literária da periferia no contexto cultural contemporâneo.

\section{Antropofagia e periferia: agenciamentos possíveis}

De fato, há um impasse de fundo no empenho da literatura em denunciar a situação de pobreza e desigualdade da imensa massa da população em um país periférico como o Brasil, dado que a condição, via de regra, erudita da literatura a transforma em um objeto de circulação restrita, destinado a uma pequena parcela da população, em geral aquela que não faz parte do grupo dos excluídos. Mesmo que se constitua em um "direito incompressível", como postula Candido (2004), a literatura produzida no círculo das instituições burguesas acaba fracassando em suas aspirações emancipatórias, reforçando, muitas vezes, a cisão entre o público letrado e o contingente pouco escolarizado. Esse dilema é expresso na conhecida frase de Oswald de Andrade: "Um dia a massa irá comer o biscoito fino que fabrico"6 - afirmação de resto problemática, pois,

\footnotetext{
6 Conforme anota Haroldo de Campos, "Num debate com Rossini Camargo Guarnieri, registrado por Mário da Silva Brito, rebatendo a tese de que há uma poesia que é entendida imediatamente pelo povo e outra que a ela
}

se, por um lado, ela assinala a promessa de democratização da arte, trazendo à tona o problema da falta de acesso da massa à cultura produzida nos círculos eruditos; por outro, causa um certo incômodo, pois contém implicitamente a ideia de simples "consumo" da alta cultura pelas classes populares, numa via de mão única que reafirma o lugar do artista e do intelectual como uma espécie de "doador" privilegiado (OLIVEIRA, 2013, p. 206).

A hipótese do deslocamento antropofágico no exame da literatura marginal periférica aqui proposta põe em questão a posição privilegiada de escritores, críticos e leitores, todos pertencentes à mesma classe e ao restrito círculo literário, com poucas variações de gosto, invariavelmente afinado com um "cosmopolitismo cultural burguês", conforme destaca Silviano Santiago (2004). Vale lembrar ainda a crítica de Oswald, ao reconhecer que havia qualquer coisa de mal compreendida e ingênua na experiência vanguardista, que ignorava a origem social e o fundo político dos propósitos daquela geração.

Em estudos recentes, como os do antropólogo brasileiro Eduardo Viveiros de Castro (2002), o conceito oswaldiano de antropofagia vem sendo retomado à luz do "perspectivismo ameríndio", que reelabora os termos das relações culturais. Questões como identidade e alteridade, tomadas na perspectiva dos modos de pensar e conceber as relações entre os seres da natureza dos povos ameríndios, projetam um entendimento da cultura em termos relacionais, em que a troca, não a identidade, é o valor fundamental a ser afirmado, o que confere uma nova potência ao conceito de antropofagia, exigindo da crítica análises dos fenômenos literários conectados de forma mais densa às formas de vida e às práticas culturais.

As formulações aqui brevemente apresentadas dão conta da persistência da antropofagia na compreensão da literatura marginal periférica como fenômeno cultural, integrado à dinâmica do sistema literário brasileiro. No quadro de desequilíbrios e injustiças de nossa experiência social e da exclusão sistemática da alteridade, a operação antropofágica surge como potência transformadora, revertendo o valor oposto - a morte, a tirania, a exclusão - em valor favorável - a comunhão coletiva, a alegria, a integração. Nesses termos, a compreensão dos deslocamentos produzidos pela literatura marginalperiférica, no interior do sistema literário brasileiro, requer a pesquisa minuciosa dos agenciamentos implicados nas formas estéticas associadas à voz e aos lugares de fala dos sujeitos marginais.

se opõe, nefelibata e egoísta, Oswald sustentava: "É preciso dar cultura à massa", "a melhor poesia atinge o povo pela exegese"; e mais, num jogo de palavras carregado de significado: "a massa ainda comerá o biscoito fino que fabrico" (1971, p. 55). 


\section{Referências}

ANDRADE, Oswald. A utopia antropofágica. São Paulo: Globo, 1990.

ANDRADE, Oswald de. Serafim Ponte Grande. 2. ed. São Paulo: Global, 1985.

ANDRADE, Oswald. O rei da vela. In: Obras Completas. Rio de Janeiro: Civilização Brasileira, 1973, p. 115-116.

BHABHA, Homi. O local da cultura. Trad. Myriam Ávila, Eliana L. L. Reis e Gláucia R.Gonçalves. Belo Horizonte: Editora UFMG, 1998.

CAMPOS, Haroldo. Uma poética da radicalidade. In: ANDRADE, Oswald. Obras completas. Rio de Janeiro: Civilização Brasileira, 1971. p.9-62. VII: Poesias reunidas.

CAMPOS, Haroldo. Metalinguagem \& outras metas. São Paulo: Perspectiva, 2013.

CANDIDO, Antonio. Formação da literatura brasileira. Belo Horizonte, Rio de Janeiro: Itatiaia, 1997. v. 1.

CANDIDO, Antonio. A educação pela noite \& outros ensaios. São Paulo: Ática, 1987.

CANDIDO, Antonio. Vários escritos. São Paulo: Duas Cidades, 2004.

CEVASCO, Maria Elisa. Para ler Raymond Williams. São Paulo: Paz e Terra, 2001.

FAUSTO, Carlos. Cinco séculos de carne de vaca: antropofagia literal e antropofagia literária. Nuevo Texto Critico, v. XII, n. 23/24, 1999. https://doi.org/10.1353/ ntc. 1999.0021

FERRÉZ (org.). Literatura marginal: talentos da escrita periférica. São Paulo: Global, 2005.

NASCIMENTO, Érica Peçanha do. Vozes marginais da literatura. Rio de Janeiro: Aeroplano, 2009.

OLIVEIRA, Rejane Pivetta. Literatura como ferramenta para pensar e Intervir no mundo. Revista da Anpoll, v. 1, n. 35, 2013 .

PATROCÍNIO, Paulo Roberto Tonani do. Escritos à margem: a presença de autores de periferia na cena literária brasileira. Rio de Janeiro: 7Letras, FAPERJ, 2013. https://doi. org/10.17771/pucrio.acad.16720

RIBEIRO, Djamila. O que é lugar de fala? Belo Horizonte: Letramento; Justificando, 2017. https://doi.org/10.1590/s010471832019000200015

RUFFINELLI, Jorge; ROCHA, João César Castro. Antropofagia hoje? Oswald de Andrade em cena. São Paulo: Realizações, 2011. https://doi.org/10.1111/j.1557203x.2012.01155 10.x
SANTIAGO, Silviano. Uma literatura nos trópicos. Rio de Janeiro: Rocco, 2000.

SANTIAGO, Silviano. O cosmopolitismo do pobre. Belo Horizonte: Editora da UFMG, 2004. https://doi.org/10.1353/ lbr.2005.0021

SCHWARZ, Roberto. Os pobres na literatura brasileira. São Paulo: Brasiliense, 1983.

SCHWARZ, Roberto. Ao vencedor, as batatas. São Paulo: Duas Cidade, 1988.

SCHWARZ, Roberto. Um mestre na periferia do capitalismo. São Paulo: Duas Cidade, 1990.

SCHWARZ, Roberto. Sequências brasileiras. São Paulo: Companhia das Letras, 1999.

TENINA, Lucía; DACASTAGNÈ, Regina. Literatura e periferias. Porto Alegre: Zouk, 2019.

VAZ, Sérgio. Cooperifa: antropofagia periférica. Rio de Janeiro: Aeroplano, 2008.

VELOSO, Caetano. Verdade Tropical. São Paulo: Companhia das Letras, 1997.

VIVEIROS DE CASTRO, Eduardo. A inconstância da alma selvagem. São Paulo: Cosac\&Naify, 2002.

Recebido em: 25/1/2019.

Aprovado em: 26/11/2019.

Publicado em: 21/12/2019.

Autora:

Rejane Pivetta de Oliveira

Mestre e Doutora. Professora do Instituto de Letras da Universidade Federal do Rio Grande do Sul (UFRGS).

Orcid: https://orcid.org/0000-0002-8966-9899

E-mail: pivetta.rejane@gmail.com

Endereço: Av. Paulo Gama, 110 - Farroupilha 90040-060, Porto Alegre, RS, Brasil 